
\title{
25 Research Soure \\ The Effect of Psychosocial Work Environment on the Health-Related Quality of Life of Health Care Providers
}

\section{Bashayer Alshahrani}

Johns Hopkins Aramco Hospital

Arwa Alumran ( $\nabla$ aalumran@iau.edu.sa )

Imam Abdulrahman Bin Faisal University https://orcid.org/0000-0001-6454-3678

\section{Research}

Keywords: quality of life, psychosocial work environment, quality of health services

Posted Date: August 28th, 2020

DOI: https://doi.org/10.21203/rs.3.rs-64779/v1

License: (c) (1) This work is licensed under a Creative Commons Attribution 4.0 International License.

Read Full License 


\section{Abstract}

Background: Psychosocial work environment is a significant factor in the provision of quality health care. Understanding the psychosocial work environment in the Saudi Arabian health care system is critical in opening up new paths for future workplace interventions and the promotion of quality health care practices. We determined the relationship between psychosocial work environment and quality of life of employees in a major Saudi health care setting.

Methods: We designed a quantitative cross-sectional study conducted at King Fahad University Hospital using a Web-based, validated survey targeting all hospital employees.

Results: The study results showed that males have significantly higher quality of life and psychosocial work environment scores $(t=-2.992, p<.001)$ than females $(t=-2.07, p<0.05)$. Employees with day shifts only had significantly higher quality of life scores compared to regular rotation shifts $(t=3.228, p<$ 0.001). Pearson correlation showed a significant association between quality of life and psychosocial work environment $(r=.349, p<.001)$. The multivariable regression model showed a significant effect of psychosocial work environment, gender, and type of shift on quality of life (adjusted $r^{2}=0.2665, f=$ $16.26, p<0.001)$.

Conclusion: We anticipated that with higher quality of life, employees' productivity increases. Thus, we expected patient care to improve by increasing health care providers' quality of life scores. This study showed a significant correlation between psychosocial work environment and quality of life.

\section{Introduction}

The psychosocial work environment (PWE) is a significant factor in the provision of quality health care. According to Teles, Barbosa (1), psychosocial work conditions at a health care facility may positively or negatively affect health care outcomes. Often, workers in health care facilities are exposed to stressful work conditions that hinder the delivery of quality health care. As such, understanding the PWE in the Saudi Arabian health care system is critical in opening up new paths for future workplace interventions and the promotion of quality health care practices.

Saudi Arabia's Vision 2030 announced by Crown Prince Mohammad bin Salman highlights strategies focused on national transformation and the improvement of the quality of life in Saudi Arabia (2).

The National Transformation Program 2020, one of the Vision 2030 initiatives, outlined the theme of health care transformation, which can be easily achieved by considering the work environment. The Saudi National Transformation Program aims to achieve three main objectives: a vibrant society, a thriving economy, and an ambitious nation. The first theme of the Saudi National Transformation Program is transforming health care as a way to achieve a vibrant society, which involves creating a comprehensive, effective Saudi health care system and continually improved health services and 
satisfaction. Improving the quality and efficiency of health care services is one of the main strategies of the program to transform health care.

Health care quality is a broad subject with many specific fields, and an urgent need to improve the quality of health care services exists in any organization, thus improving the use of resources to provide desirable care for patients that is of sound quality. A considerable effort should be made at all levels, and all employees should collaborate to achieve this vision.

Employees are one of the main pillars that can affect the quality of health care service provided to patients. Health-related quality of employees' lives is a considerable factor that directly affects the services provided to patients. Health care providers' health-related QoL is investigated in this research, as well as how significantly it is affected by the PWE. From this research, we can identify possible factors that could be controlled and corrected to improve employees' QoL and PWE, thus improving the overall quality of health services.

This study investigates the relationship between two significant factors in the Saudi Arabian health care system. The independent variable is the PWE, whereas the dependent variable is the health-related QoL of health care providers. Therefore, the research focuses on understanding the relationship between the two variables to provide insights on how to improve workplace conditions in Saudi Arabian health care facilities, which will in turn improve their health-related QoL and thus allow practitioners to provide better quality health care.

The primary objective of this research is to determine the relationship between PWE and the healthrelated QoL of health care providers in Eastern Saudi Arabia.

\section{Methods}

This a quantitative cross-sectional study using an online survey. The survey mainly measures the healthrelated QoL score as a dependent variable and PWE as an independent variable, and it includes questions to identify demographic and other variables.

Data was collected only in King Fahad University Hospital in Khobar, Eastern Saudi Arabia. All hospital departments were included in the study.

All health care providers were included in the study: physicians, nurses, administrative personnel, and allied health professionals (radiology, pharmacy, laboratory, physical therapy, nutrition, and respiratory therapy).

Data was collected using an online survey distributed using mobile messaging applications and e-mail. A barcode linked to the online survey was also printed and distributed to hospital employees. Data were collected in March 2019. Ethical approval was obtained from the relevant institutional review board. The survey was conducted confidentially without exposing personal information. 
The instrument used in data collection is from two validated surveys Pejtersen $(3,4)$. The instrument consists of three sections: 20 questions measuring the health-related QoL score, 20 questions measuring the PWE, and eight questions to identify demographic and other variables related to personal information about the participants (e.g., gender, age, profession, and type of shift).

The QoL score was calculated by adding the responses of the 20 items that measure QoL, whereas the PWE score was calculated by adding the responses of the 20 items that measured the PWE. Higher scores indicated better QoL and PWE.

All variables were summarized in a univariate analysis using counts, percentages, $M$, and $S D$. Bivariate analysis was conducted using a $t$-test and analysis of variance. Graphical presentations are included to show the bivariate associations. Further, multivariable analysis was conducted using a multivariable regression model.

\section{Results}

The aim of the study is to determine the relationship between PWE and QoL of health care workers. We examined the relationship between PWE, age, gender, educational level, profession, working shift, and nationality and QoL. Univariate analysis was conducted to summarize the variables in the study, bivariate analysis was conducted to measure associations between the independent variables (e.g., PWE score, demographic variables, and shift type) and the dependent variable (QoL score) using a $t$-test and analysis of variance, and multivariable analysis was conducted for further exploration of associations.

The response rate was $90.7 \%(n=128)$ from a targeted sample size 141 participants, with confidence interval of 8 and $95 \%$ confidence level. The participants were distributed almost equally between males (50.7\%) and females (49.2\%). Most participants had direct contact with patients. Of respondents, $32.81 \%$ were physicians, $14.1 \%$ were nurses, and $31.25 \%$ were allied health workers (radiology, pharmacy, laboratory, physical therapy, nutrition, respiratory therapy). The rest of the participants $(21.48 \%)$ have administrative positions. Most of the respondents (95\%) had regular rotation shifts compared with only $5 \%$ of workers who had morning shifts. Saudi workers represented the majority of the sample, whereas 31 (25\%) were from other countries (e.g., Bahrain, Egypt, Jordan, South Africa, India, Pakistan, and the Philippines). Almost half (48.44\%) of the participants were from 31 to 40 years old. Most respondent had a bachelor's degree (62.5\%), whereas $35 \%$ had a graduate degree or higher (Table 1 ). 
Table 1

- The Descriptive Statistics of the Participants

\begin{tabular}{|ll|}
\hline Variables & Frequency N (Percentage\%) \\
\hline Gender & $63(49.2 \%)$ \\
Female & $65(50.7 \%)$ \\
\hline Age & \\
$21-30$ years old & $39(30.46 \%)$ \\
$31-40$ years old & $62(48.44 \%)$ \\
$41-50$ years old & $19(14.84 \%)$ \\
$51-60$ years old & $8(6.25 \%)$ \\
\hline Profession & \\
Administrative & $28(21.87 \%)$ \\
Physician & $42(32.81 \%)$ \\
Nursing & $18(14.1 \%)$ \\
Allied Health & $40(31.25 \%)$ \\
\hline Education & \\
Secondary/high school & $3(2.34 \%)$ \\
Bachelor's degree & $80(62.5 \%)$ \\
Master's degree & $16(12.5 \%)$ \\
PhD degree or higher (Or Board certified) & $29(22.66 \%)$ \\
\hline Shift & $33(25.78 \%)$ \\
Days Only & $95(74.22 \%)$ \\
Regular rotation shifts & \\
\hline Nationality & $97(75.78)$ \\
Saudi & $(24.22)$ \\
Non-Saudi & \\
\hline
\end{tabular}

Table 2 shows the significant bivariate associations in the study. There was a significant difference between females $(t=-2.992, p>.001)$ and males $(t=-2.07, p>.05)$ regarding their QoL and PWE (Fig. 1 \&Figure 2). In addition, a significant difference was found between participants who worked day shifts and participants who worked regular rotation shifts regarding their $\mathrm{QoL}(t=3.228, p>.001)$. Furthermore, 
PWE and QoL were significantly positively correlated $(r=0.349, p>.001)$, as shown in Fig. 3 . On the other hand, participants' education, nationality, age, and profession had no significant association with their QoL or PWE scores. 
Table 2

- Bivariate Analysis between different independent variables with quality of life and psychological work environment

\begin{tabular}{|c|c|c|c|c|}
\hline & $\begin{array}{l}\text { QoL } \\
\text { Mean (SD) }\end{array}$ & $\begin{array}{l}\text { Test } \\
\text { statistic }\end{array}$ & $\begin{array}{l}\text { PWE } \\
\text { Mean (SD) }\end{array}$ & Test statistic \\
\hline $\begin{array}{l}\text { Gender } \\
\text { Female } \\
\text { Male }\end{array}$ & $\begin{array}{l}63.32 \\
(7.1) \\
66.95 \\
(6.5)\end{array}$ & $t=-2.992^{\star *}$ & $\begin{array}{l}68.19 \\
(11.7) \\
72.06(9.3)\end{array}$ & $t=-2.07 *$ \\
\hline $\begin{array}{l}\text { Age } \\
21-30 \text { years old } \\
31-40 \text { years old } \\
41-50 \text { years old } \\
51-60 \text { years old }\end{array}$ & $\begin{array}{l}64.33 \\
(7.5) \\
65.13 \\
(6.6) \\
\\
65.26 \\
(8.1) \\
68.38 \\
(5.8)\end{array}$ & $f=1.327$ & $\begin{array}{l}68.33 \\
(11.4) \\
70.32 \\
(10.6) \\
70.42(8.8) \\
77.00(9.2)\end{array}$ & $f=1.168$ \\
\hline $\begin{array}{l}\text { Profession } \\
\text { Administrative } \\
\text { Physician } \\
\text { Nursing } \\
\text { Allied Health }{ }^{\dagger}\end{array}$ & $\begin{array}{l}65.86 \\
(5.8) \\
65.38 \\
(6.7) \\
63.83 \\
(8.5) \\
64.66 \\
(7.1)\end{array}$ & $f=0.730$ & $\begin{array}{l}71.59(8.1) \\
74.31(9.6) \\
65.00 \\
(13.1) \\
67.16 \\
(10.2)\end{array}$ & $f=1.279$ \\
\hline $\begin{array}{l}\text { Education } \\
\text { Secondary or high school } \\
\text { Bachelor's degree } \\
\text { Master's degree } \\
\text { PhD degree or higher (Or Board } \\
\text { certified) }\end{array}$ & $\begin{array}{l}64.33 \\
(8.5) \\
64.78 \\
(7.3) \\
65.94 \\
(6.4) \\
65.66 \\
(6.7)\end{array}$ & $f=1.007$ & $\begin{array}{l}73.00(2.6) \\
68.98 \\
(10.4) \\
66.75 \\
(12.1) \\
74.97(9.7)\end{array}$ & $f=1.047$ \\
\hline $\begin{array}{l}\text { Shift } \\
\text { Days Only } \\
\text { Regular rotation shifts }\end{array}$ & $\begin{array}{l}66.25 \\
(6.9) \\
61.82 \\
(6.5)\end{array}$ & $t=3.228 * \star$ & $\begin{array}{l}69.68 \\
(10.6) \\
71.48 \\
(10.9)\end{array}$ & $t=-0.838$ \\
\hline
\end{tabular}




\begin{tabular}{|lllll|}
\hline & $\begin{array}{l}\text { QoL } \\
\text { Mean (SD) }\end{array}$ & $\begin{array}{l}\text { Test } \\
\text { statistic }\end{array}$ & $\begin{array}{l}\text { PWE } \\
\text { Mean (SD) }\end{array}$ & Test statistic \\
\hline Nationality & 66.26 & $t=1.043$ & 69.71 & $t=-0.263$ \\
Saudi & $(5.5)$ & & $(10.9)$ & \\
Non-Saudi & 64.74 & & 70.29 & \\
${ }^{*} \mathrm{p}<0.05,{ }^{* *} \mathrm{p}<0.001, * * * \mathrm{p}<0.0001$ & $(7.5)$ & & & \\
${ }^{\dagger}$ Allied Health: Radiology, Pharmacy, laboratory, physical therapy, nutrition, respiratory therapy & \\
\hline
\end{tabular}

A multivariable linear regression model was created, where the outcome variable was the QoL score and the independent variables were all the significant variables from the bivariate analysis (i.e., gender and shift type; Table 3). Although the model was significant, the adjusted $r^{2}(0.2665)$ is not high $(p<.0001)$. Males had significantly better QoL scores compared to females even after adjusting for other variables ( $B$ $=3.7, t=3.39,95 \% \mathrm{Cl}[1.57,5.961], p<.001)$. Further, participants who had regular rotation shifts had significantly lower QoL scores even after adjusting for other variables in the regression model $(B=-5.7, t=$ $-4.59,95 \% \mathrm{Cl}[-8.19,3.25], p<.001)$. PWE influenced the model significantly $(B=0.22, t=4.22,95 \% \mathrm{Cl}[0.12$, $0.32], p<.001)$.

Table 3

- Multivariable regression model

\begin{tabular}{|c|c|c|c|}
\hline \multicolumn{4}{|c|}{$\begin{array}{l}\text { Outcome: QoL } \\
F(3,123)=16.26 \text {, Adj R-squared }=0.2665 \text {, Prob }>F=0.0000\end{array}$} \\
\hline Variable & Coefficient & $\mathrm{t}$ & $95 \% \mathrm{Cl}$ \\
\hline Psychosocial work environment & 0.2169022 & $4.22^{\star \star \star}$ & $0.1151673,0.3186371$ \\
\hline Gender & Constant & $3.39 * \star \star$ & $1.566398,5.96096$ \\
\hline Female & 3.763679 & & \\
\hline \multicolumn{4}{|l|}{ Male } \\
\hline Shift & Constant & $-4.59 * * \star$ & $-8.19215,-3.251933$ \\
\hline Days only & -5.722041 & & \\
\hline \multicolumn{4}{|l|}{ Regular rotation shifts } \\
\hline${ }^{*} \mathrm{p}<0.05,{ }^{* *} \mathrm{p}<0.001,{ }^{* * *} \mathrm{p}<0.000$ & & & \\
\hline
\end{tabular}

\section{Discussion}


Health care systems play a crucial role in safeguarding the continuous progress and growth of human beings, in which case it is imperative that countries maintain a significantly high level of quality. This study was carried out with the aim of assessing the effects of PWE on the QoL of workers while also determining the factors that could have a bearing on the relationship.

This objective of the study is supported by the Saudi National Transformation Program 2020 and as part of the initiative that aims to elevate the QoL and services standards in Saudi Kingdom health care facilities.

There was an apparent significant association between PWE and QoL. Other characteristics were measured in relation to the PWE and the QoL scores, of which PWE and QoL scores were significantly different between males and females. Additionally, participants who had regular rotation shifts had lower QoL scores compared to those with only day shifts.

After adjusting for individual and job characteristics there remained an association between gender (male or female), type of shift (day only, night only, or rotation shift), and PWE with the quality of workers' lives.

High pressure at work and adverse psychosocial working conditions have a greater chance to be associated with poor health-related QoL (5). There is a significantly high correlation between PWE and the QoL of hospital employees, which answers the major aim of the study (1). Similar results from studies conducted on municipal schools in Brazil and primary health care employees supports the results of the current study $(1,6)$. QoL is directly affected by the quality of PWE due to the long time spent at work by the employees, which could also affect other aspects of life if it is not adjusted (e.g., social life, health condition, mental condition, and burnout). Further investigations can be useful to control the factors addressed in this research.

The study shows significant differences in the QoL score and PWE between genders; female respondents had lower QoL and lower PWE than males. Pretty, McCarthy (7) found similar results by presenting the association between job stress and diabetes II among women as being higher than it is among men.

In addition, depression levels in females are significantly higher than males due to high levels of stress and perceived low levels of fulfillment in females compared to males (8). The difference between males and females in QoL and PWE could be due to different factors such as the preciseness in self-reporting, specifically when describing depressive feelings (9). Further, according to Grant, Robinson (10), females' levels of tolerance for physical and psychosocial stress is lower than it is in males.

Kulwicki, Miller (11) suggested that females in the Arab communities face varying challenges compared to their male counterparts (e.g., transportation difficulties, gender preferences related to embarrassment in exposing female patients to male workers, and problems seeking and accepting health care from male providers). However, some of the challenges have been overcome with the transformation of Saudi Arabia. 
Furthermore, the results indicate an association exists between workers' QoL and the nature of work shifts. Indeed, employees with regular rotation shifts indicated significantly lower QoL scores compared to employees who had day shifts only. Previous studies support our result regarding the relationship of working shift with QoL. For instance, Sorić et al. (2013) found that shift employees have significantly lower levels of QoL compared with nonshift employees, which showed the adverse effect of working shifts on workers' health and social lives (5). Usually the number of employees working during regular working hours (from 8:00 am to 3:00 pm) exceeds the number of employees working after 3:00 pm. It is noteworthy that the reduction in workers increases the load on them after regular working hours. In this case, employees who work during the night shift have a higher risk of depression, which could be related to the immense pressure and loneliness at the workplace because of fewer employees and quietness at night (12). The persistent modification of the biological clock and adjustment of sleeping time from day to night for rotational shift workers causes sleeping disorder and high levels of anxiety (5).

Retaining employees and motivating them to do their best is major challenge for employers. Most health care workers belonged to generations $X$ (Industrial Revolution) and $Y$ (Information Revolution), and both generations are very similar in job motivations. Chance for promotion and steady employment are main motivators for generations $X$ and $Y$, but neither with Generation $Z$ (Social Revolution(13). People from Generation X were born in the late 1970s and early 1980s, whereas people from Generation $Y$ were born in the 1980s and 1990s and people from Generation Z were born in the 1990s and raised in the 2000s (14). Dealing with each generation requires special ways to retain them, and nowadays employees are looking for QoL, quality of work environment, quality of role opportunity, learning, and rewards. If employers do not have mechanisms for these factors then retention will be at risk.

\section{Conclusion}

The primary objective of this research was to determine the relationship between PWE and health-related QoL of health care providers in Eastern Saudi Arabia. The results show an association. QoL is related to gender, working shift, and PWE. On the other hand, there is association between gender and PWE.

The study offers a predictor model that forecasts workers' QoL and creates functional criteria that could support quality project initiatives to enhance the quality of health care services.

The major study limitations were the variations of data collection methods that prevented the exact number of surveys from being distributed and the limited time to conduct the study, which led to a low sample size taken from one study setting (King Fahad Hospital of the University). Another limitation was the low response rate, which may have been because of various factors, such as participants' busy schedules and lack of interest in the study.

We highly recommend carrying out similar studies in the future in different health care facilities and on larger samples to allow for comparisons of other work environments in relation to the employees' QoL scores. There is an urgent need to research the question of whether female employees' QoL is lower than 
males across the country, or whether it is only in the study setting. In addition, the need exists to understand whether females' QoL scores are related to their professions.

We anticipate that with higher QoL scores, employees' productivity increases. Thus, patient care is expected to improve by increasing the health care providers' QoL scores.

\section{Declarations}

Ethics approval and consent to participate: Ethical approval obtained from Institutional Review Board in [blinded for review]. The Survey was conducted confidentially without any personal information exposed. Consent is perceived upon completion of the survey as indicated to the respondent in the survey cover letter.

Availability of data and materials: The datasets used in the current study are available from the corresponding author on reasonable request.

Competing interests: The authors declare that they have no competing interests

Funding: The authors declare that there is no funding source for this manuscript

Acknowledgement: The authors would like to thank Papercheck (papercheck.com) for their English language editing.

\section{References}

1. Teles MAB, Barbosa MR, Vargas AMD, Gomes VE, e Ferreira EF, de Barros Lima AME, et al. Psychosocial work conditions and quality of life among primary health care employees: A cross sectional study. Health and Quality of Life Outcomes. 2014;12(1):72.

2. Mitchell B, Alfuraih A. The Kingdom of Saudi Arabia: Achieving the Aspirations of the National Transformation Program 2020 and Saudi Vision 2030 Through Education. Journal of Education and Development. 2018;2(3):36.

3. Pejtersen JH, Kristensen TS, Borg V, Bjorner JB. The second version of the Copenhagen Psychosocial Questionnaire. Scandinavian journal of public health. 2010;38(3_suppl):8-24.

4. Rockwood TH, Church JM, Fleshman JW, Kane RL, Mavrantonis C, Thorson AG, et al. Fecal Incontinence Quality of Life Scale: quality of life instrument for patients with fecal incontinence. Dis Colon Rectum. 2000;43(1):9-16.

5. Silva LS, Barreto SM. Adverse psychosocial working conditions and poor quality of life among financial service employees in Brazil. Journal of Occupational Health. 2012;54(2):88-95.

6. Fernandes MH, Rocha VMd. Impact of the psychosocial aspects of work on the quality of life of teachers. Brazilian Journal of Psychiatry. 2009;31(1):15-20. 
7. Pretty GM, McCarthy ME, Catano VM. Psychological environments and burnout: Gender considerations within the corporation. Journal of Organizational Behavior. 1992;13(7):701-11.

8. Kessler RC. Epidemiology of women and depression. Journal of affective disorders. 2003;74(1):5-13.

9. Ghubash R, Daradkeh TK, Al Naseri KS, Al Bloushi NBA, Al Daheri AM. The performance of the Center for Epidemiologic Study Depression Scale (CES-D) in an Arab female community. International Journal of Social Psychiatry. 2000;46(4):241-9.

10. Grant VJ, Robinson E, Muir P. Sex ratios in healthcare occupations: population based study. Bmj. 2004;328(7432):141-2.

11. Kulwicki AD, Miller J, Schim SM. Collaborative partnership for culture care: Enhancing health services for the Arab community. Journal of Transcultural Nursing. 2000;11(1):31-9.

12. Øyane NM, Pallesen S, Moen BE, Åkerstedt T, Bjorvatn B. Associations between night work and anxiety, depression, insomnia, sleepiness and fatigue in a sample of Norwegian nurses. PloS one. 2013;8(8):e70228.

13. Montana PJ, Petit F. Motivating and managing generation $x$ and $y$ on the job while preparing for $z$ : $A$ market oriented approach. Journal of Business \& Economics Research. 2008;6(8):35-9.

14. Tulgan B. Meet Generation Z: The second generation within the giant" Millennial" cohort. Rainmaker Thinking. 2013(125).

\section{Figures}

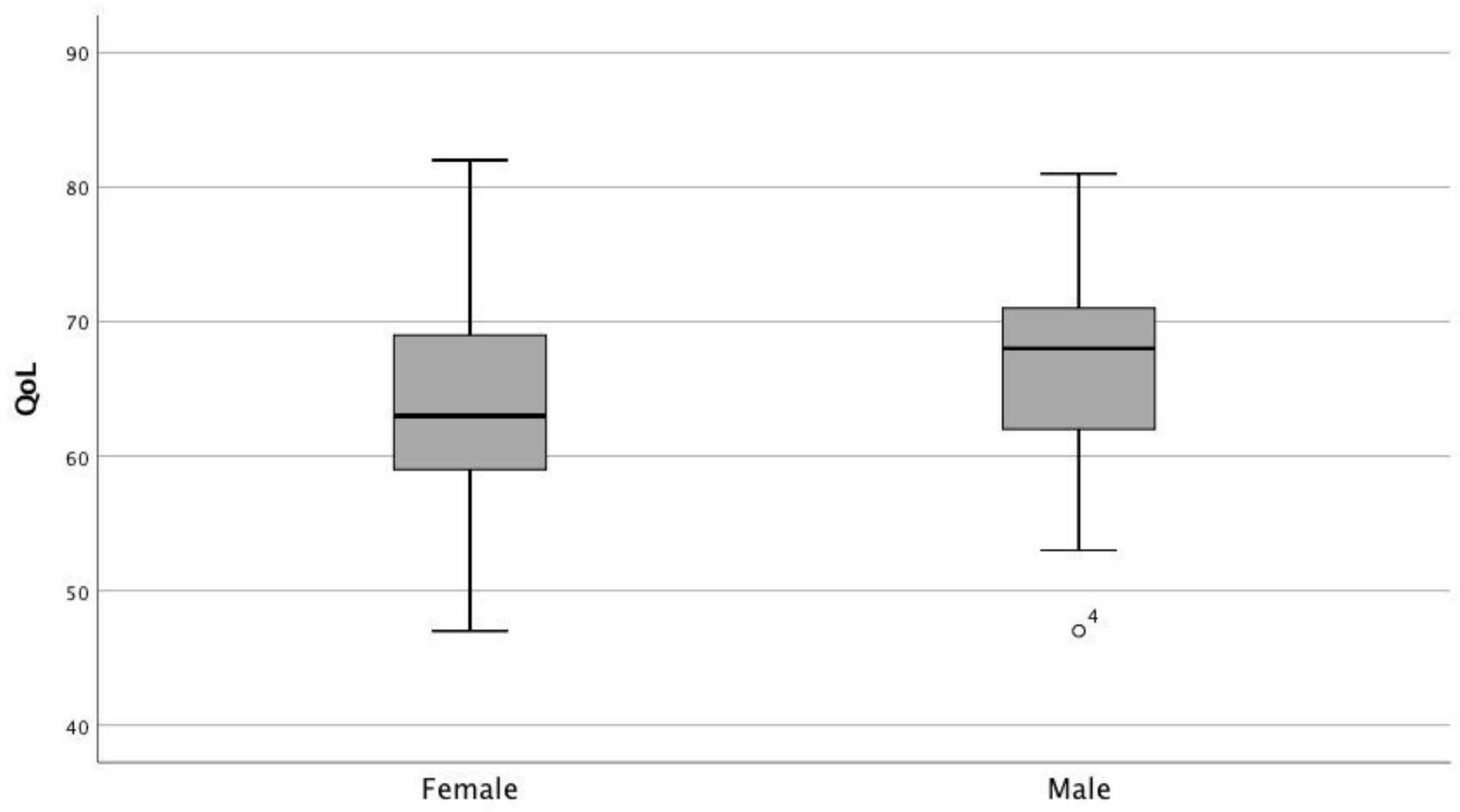

Gender 
Figure 1

Difference in QoL Scores Between Males and Females

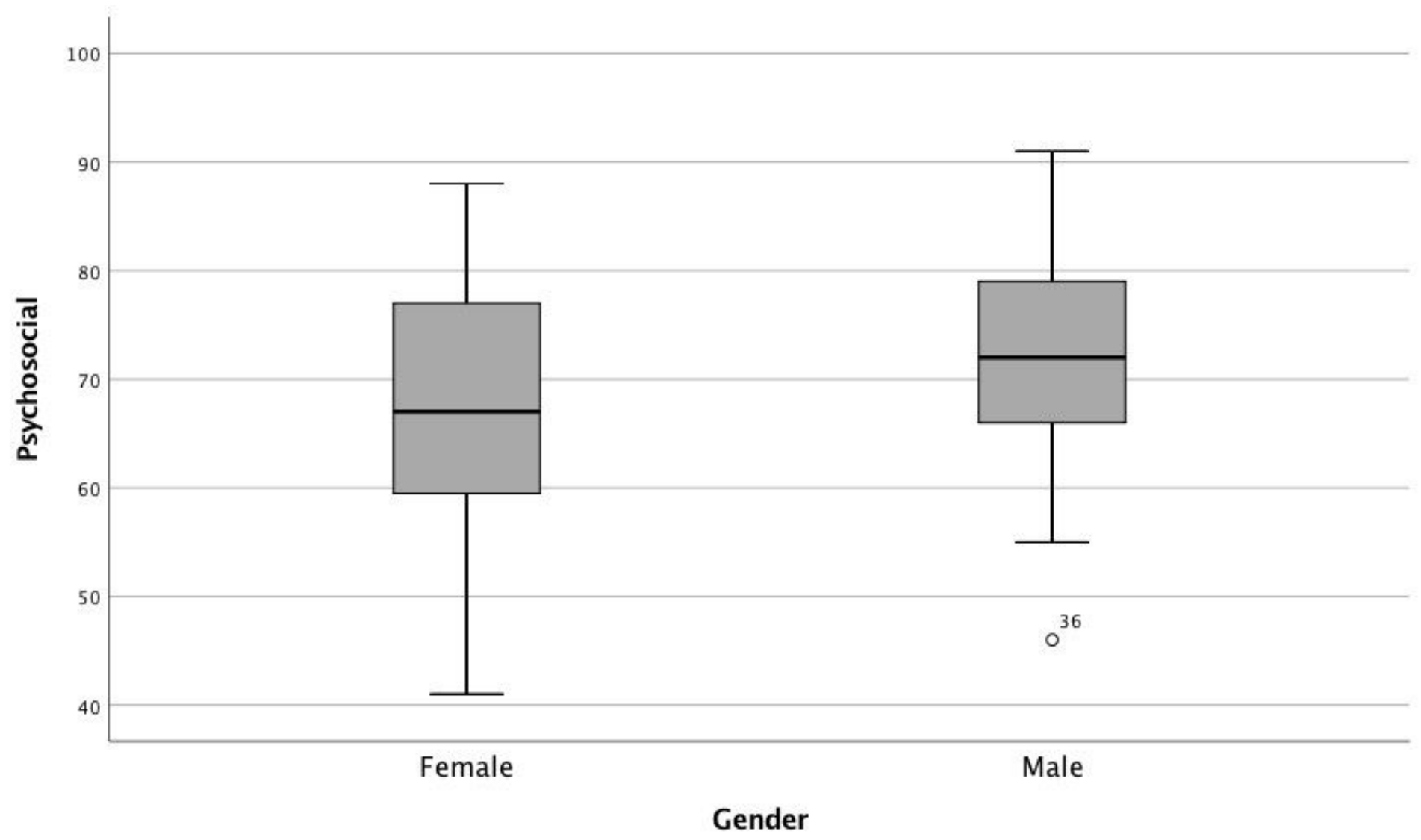

Figure 2

Difference in PWE Scores Between Males and Females 


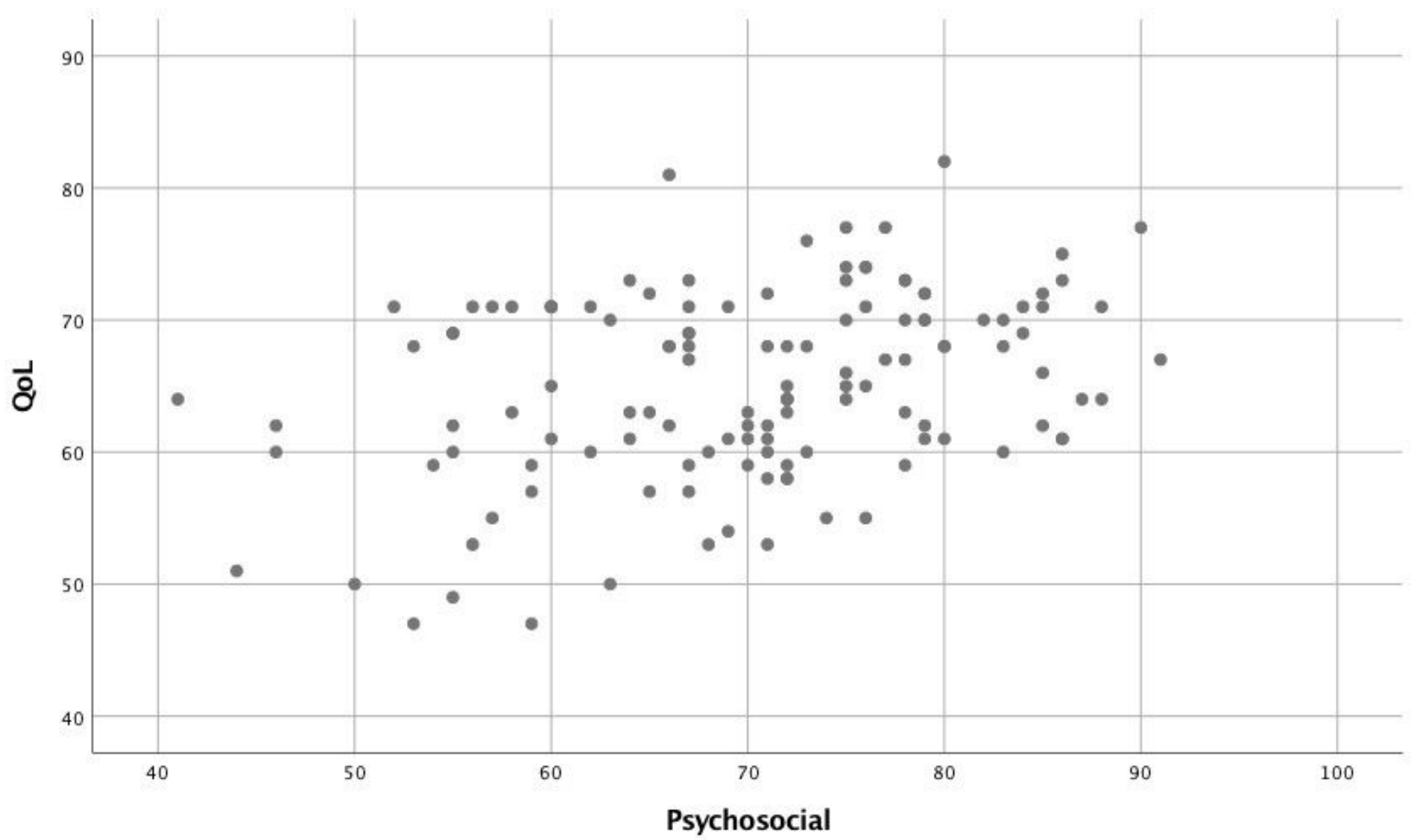

Figure 3

Relationship Between QoL Scores and PWE Scores of the Participants 